\title{
Increasing Student Motivation To Learn By Making Computer Game Technology More Engaging: Measurable Outcomes That Determine Success
}

Mark D. Mann, Texas Woman's University, USA

\begin{abstract}
In the $21^{\text {st }}$ Century, Educators are called to thinking in broader terms about the purpose of technology in engaging learners to work on tasks that are meaningful to them. Through technology, as described in this paper, the researcher has attempted to broaden student engagement level by developing a more engaging online game framework. The research attempted to increase engagement by modifying a less goal oriented maze game into a sporting challenge called Downhill Skier. In creating simulation software for the individual sport of downhill skiing, the Downhill Skier app was developed using the elm programming language. Since Elm is a relatively easy programming language to learn, Elm code can be modified and shaped to ones intended purpose. Using the EGameFlow Survey, an instrument that has been tested for internal and external validity, the research demonstrated that engagement levels were increased, in seven of the eight categories that EGameFlow measures, by changing the nature of the game from a maze walk through into an e-sport challenge.
\end{abstract}

Keywords: Computer Game Technology; Student Engagement; Elm Programming Language

\section{INTRODUCTION}

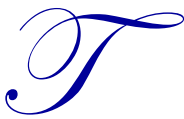

he "Digital Native" is mentioned in Kiili's work (Kiili, 2005), as the 21st century learner who has been raised in a different environment to that of the pre-21st century learner. The pervasive technology that surrounds most of their lives, for example: smart phones (with all of their features), laptops, tablets, and/or games consoles, has created a new generation of learners that reason differently than their pre-21st century counterparts (the Digital Immigrants) and therefore need to be educated differently. As learners and consumers of information, Digital Natives are more naturally inclined to learn from web blogs and social media, rather than by reading books. In this context, then, computer games can be seen as being a more natural means of acquiring and processing information to them.

\section{LITERATURE REVIEW}

Literature on successful game development has indicated that repetition (where students take time to master a level of difficulty until they attain that level) comes without thinking about it, and that most game players will attempt the game until they attain the next level of the game. As Gee (2016) has contended, this process is fundamental to learning, as gamers will reflect on what they have discovered in the process of advancing a level in a game. Having reflected, the player will develop a hypothesis on how the game world operates. With this hypothesis in mind, the player re-probes the game world in order to test whether the hypothesis is correct or not. In the event of the hypothesis being incorrect (i.e. the player fails to make progress or complete the current level), the player will then start from the beginning and re-probe, reflect and then re-develop/re-test their hypothesis. Gee also argues that the probe, reflect, hypothesize, re-probe process will also lead the player/learner to engage in critical thinking.

The other main argument for the educational use of computer or smartphone games is that they generate high levels of engagement and therefore lead to interested and motivated learners. Motivational theory has long considered the 
keys to successful learning involve engagement, and that motivated learners have greater involvement in the process of education. In this context, game players are willing to spend hours of their time in order to master a certain game feature, a level within the game, or the game itself. A successful computer game involves a mixture of interactivity, motivation to complete the game, and a challenge. The level of challenge should be evenly balanced so that the game is not too hard to complete, nor too easy. Game mechanics are also important to participant motivation. The aspects of game mechanics include the player being able to identify the goals/rewards/penalties of the game, the level of challenge given to the player and the various mechanisms employed (such as: racing against the clock) that make the game enjoyable. The literature on motivation breaks down motivation into two overall types: Intrinsic \& Extrinsic Motivation. Intrinsic motivation is considered internal to the individual. A person who is intrinsically motivated will chose to engage in an activity because they find it inherently interesting and seek to participate due to gaining enjoyment from the activity. On the other hand, extrinsic motivation is considered external to the individual. That is, the individual will participate because they feel obliged or required to do so. What is vital is the integration of "flow" and really getting into a game and gaining benefit from the game that, "teaches everything it has to offer before the player stops playing" (Cowley, et.al. 2008).

"Flow Theory" is a set of conditions, which if experienced at the same time, can cause the learner to enter into a flow state of mind. When learners are in a Flow state, they will be intensely engaged in their current activity, to the exclusion of everything else. This proposed level of engagement is very appealing within the education sector and is regarded by Gee (2016) as one of the most persuasive reasons for the use of games within the education system. Two important characteristics of the flow state are total immersion and time loss. Total immersion means that the learner should be so engaged in the current activity that the outside world, and fear of failure, fades into the background. Time loss refers to the fact that the activity would be so engaging that the learner loses track of time, and in that context, time has flown by. The ideal balance is represented by a Flow Channel whose rules are, "as a learner's skill increases, the level of challenge will also need to be increased" (Bjerkhaug, et.al. 2011) so that the learner will remain in the flow of the activity.

\section{The Programming Paradigm}

As an attempt to engage 21 st century students with a computer game and learning environment that would be engaging and cultivate the flow experience highlighted in the literature review of this paper, I set out to create an experimental website called http://chirp.life/. The chirp.life website was created for 21 century students to play games and be engaged by the games and be motivated to play them until mastery was achieved. The game would need to be playable via the web on a laptop computer or on a smartphone. There were many considerations that had to be made from a technical perspective, but, in the end, this researcher settled on a programming language and paradigm that would give tools that could be used to create a game for the stated purposes.

The programming language that was chosen to develop the game is a language called ELM. (Czaplicki, 2012) The language can be found at http://www.elm-lang.org/. Originally, the researcher had thought of using a purely JavaScript implementation, but found that limited programming experience made it difficult to go into the source code and modify the games in JavaScript in such a way that was needed or possible. Without the ability to customize the game, and the student's experience of the game that they were playing, to fit the flow criteria benchmarks of engagement and enjoyment of the game, the search had to continue until ELM was found. One of the great things about ELM are the tutorials that are provided to help the novice programmer get started on building games locally on their computers, be able view the source code, and edit and modify that code as they see fit. Also, because ELM in an open source programming language, most ELM programmers will share their code on repositories such as GitHub where one can download all of the source code of a particular game, study it, and learn a great deal.

\section{METHODS}

There were four ELM games that were ported by the researcher to the chirp.life website. ELM-Maze, ELMAsteroids, ELM-Snake, and ELM-Tetris Game (called Flatris). 3 of the 4 games were popular with visitors and students who had gone to the site. The ELM-Maze game was the one that had the least amount of traffic, and was thus targeted for an upgrade using the goals of engagement enhancement as outlined in the literature review. The value of the upgrade from ELM-Maze into a new game called ELM-Downhill Skier, from a student engagement 
perspective, was the independent variable of this study. The researcher surveyed a group of 48 students using the eGameFlow survey (via Google Forms), after playing the ELM-Maze game, and then again, 30 days later, after the improvements to the game were made, and the students played ELM-Downhill Skier.. A T-Test was calculated to record the possibility of a significant difference on the EGameFlow scores from before to after the improvements to the game were implemented. The modified game consists of the game player being able to adeptly manipulate the skier down the five distinct mountain runs in as short a period of time as possible. All of the runs on the downhill course were modified and were designed with the idea of the game player progressing in difficulty from one stage of the game to another with intermittent breaks between each of the runs on the skiing course.

In terms of selection of the survey to be used for quantitative data analysis, EGameFlow was selected because of it's goodness of fit with the measures of Flow and the goals of the improvement in the ELM maze game and it's transformation into ELM-downhill skier. The EGameFlow scale is a scale that "measures the experience offered by E-learning games, and helps the game designer to understand the strengths and weaknesses of the game from the learner's point of view." The eight areas measured by the EGameFlow Survey Instrument are: Concentration, Goal Clarity, Feedback, Challenge, Autonomy, Immersion, Social Interaction, and Knowledge Improvement.

\section{CONCLUSION}

The results of the study showed a significant improvement in student scores on the EGameFlow Survey. These improvements were based on student responses after playing the ELM-Maze Game and then, thirty days later, playing the ELM-Downhill Skier Game. The mean scores from the eight categories of EGameFlow showed seven of the eight categories gaining marked improvement. (See Fig. 1.) Autonomy was the only category where the mean score was lower on ELM-Downhill Skier than ELM- Maze. It is possible that creating more courses for ELMDownhill Skier and options for the game player in the ELM-Downhill Skier game will improve scores in the Autonomy category of the EGameFlow survey.

Figure 1.

\begin{tabular}{l|c|c}
\hline \multicolumn{1}{c}{ Category } & ELM- Maze (before) & ELM Downhill Skier (after) \\
\hline Concentration & 4.1 & 5.2 \\
\hline Goal Clarity & 3.3 & 3.5 \\
\hline Feedback & 4.5 & 5.2 \\
\hline Challenge & 3.2 & 5.4 \\
\hline Autonomy & 3.5 & $* 3.2$ \\
\hline Immersion & 3.6 & 5.4 \\
\hline Social Interaction & 2.9 & 4.1 \\
\hline Knowledge Improvement & 2.5 & 4.0 \\
\hline
\end{tabular}

Regarding overall statistical significance, the $\mathrm{p}$ value (where $\mathrm{a}<0.05$.) for the two independent samples $\mathrm{t}$-test was 0.018 , where $\mathrm{T}=-2.689$. Thus, the null hypothesis that the before and after scores on the EGameFlow Survey would be equal, was rejected. As the results of the study indicate, programming in ELM was a fruitful enterprise that was well received by the students playing the ELM-Downhill Skier Game. The Personal Best Leaderboard indicated significant engagement that improved interaction between participants in the online game. As a faculty member at a state university, the researcher found that students can relate to the professor/ researcher on a more engaging level as a result of the work on chirp.life and the small yet significant work that has been done in game development to engage them on "their turf" in the world of $21^{\text {st }}$ century technology. As this study has pointed out, the possibility that creating games that are engaging for learners has a strong effect on learner concentration (4.1 to 5.2), a sense of challenge (3.2 to 5.4), and the feeling of immersion (3.6 to 5.4) in the task at hand. With an overall alpha of 0.018 it is likely that the efforts made to engage and immerse the students more in the ELM-Downhill Skier game did not happen by chance. Thus, it is a productive enterprise to engage learners in ways to meet our students where they are, here, in the second decade of the $21^{\text {st }}$ century. Overall, such efforts can make a significant difference in the value the learners will attribute to the games themselves, and quite possibly to their learning experience as a whole. One aside worth mentioning is that other platforms, that don't require compilation, and are pure JavaScript examples of game 
development, are listed under the how-to tab at the Chirp.Life homepage. Seeing games developed in pure JavaScript is a good starting point, but, should lead to working with a tool like ELM where one has more control over the code that is edited, and then deployed.

\section{AUTHOR BIOGRAPHY}

Mark Mann, Ph.D., is an assistant professor of Kinesiology, Sport Coaching, at Texas Woman's University in Denton, Texas, USA. Mann is the Editor of an international Journal entitled, The Journal of Athlete Centered Coaching. Mann has 25 years of experience coaching at the International, NCAA, NAIA, High School, Club, and Youth Sport Levels. He uses the ELM Programming Language to build engaging sport simulation software.

\section{REFERENCES}

Bjerkhaug, S. W., Mathisen, R. O., \& Valtola, L. A. (2011). The Amazing City Game (Master's thesis, Institute for datateknikk og informasjonsvitenskap).

Cowley, B., Charles, D., Black, M., \& Hickey, R. (2008). Toward an understanding of flow in video games. Computers in Entertainment (CIE), 6(2), 20.

Czaplicki, E. (2012). Elm: Concurrent frp for functional graphical user interfaces. Senior thesis, Harvard University.

Gee, J. P. (2016). Gaming lives in the twenty-first century: Literate connections. G. Hawisher, \& C. Selfe (Eds.). Springer.

Kiili, K. (2005). Digital game-based learning: Towards an experiential gaming model. The Internet and higher education, 8(1), 13-24.

Meyerovich, L. Flapjax: Functional Reactive Web Programming. See http://www.cs.brown.edu/ 1meyerov/thesis8. pdf. 